\title{
Cost Effective E-Vehicle for Physically Challenged \& Aged Peoples
}

\author{
B. Balaji, R. Suganya
}

\begin{abstract}
There is always a great challenge for physically challenged and aged peoples of middle class people to move in bus stops, bus stands, hotels, working places, etc., for benefit of such peoples the cost effective E-Vehicle is designed to move from one place to another in certain level of distance. The $E$ Vehicle is a three wheeler, one wheel at front and two wheels at rear. The E-Vehicle has a comfortable seat for the person to sit and it also has a cabin to accommodate batteries and the controller setup. This E-Vehicle is nil emissive and produces very less noise. This E-Vehicle is made to have more energy efficient than the IC Engines. The Vehicle is of light weight to increase its operating efficiency. The main aim of this work is to have a comfortable travel in indoor and outdoor places.
\end{abstract}

Keywords: E-Vehicle, design, aged and physically challenged people.

\section{INTRODUCTION}

IC Engines were commonly used for the propulsion for past years which uses hydrocarbons as a fuel. These hydrocarbons were combusted in the IC Engines to produce a power which is used for propulsion. These IC Engines, during combustion process, emits huge toxic pollutants like carbon monoxide, nitrogen oxide, etc., which affects the atmosphere by increasing the earth's temperature, in turn disturbs the life cycle of living beings. In order avoid these environmental problems and to have smooth travel of people in indoor and outdoor places, this cost effective E-Vehicle plays a wonderful role in it. This E-Vehicle is pollution free, environmental friendly. Comfort travel can be made up to certain level of distance (i.e) within 15 to 20 Kilometres.

This E-Vehicle reduces the usage of IC Engine Vehicles which in turn reduces the environmental issues. There are various models of E-Vehicles in market for physically challenged peoples. But the cost is high, when it is in view of financially low and middle level peoples. The aim of this work is to design and assemble a comfortable and inexpensive E-Vehicle for physically challenged and aged peoples. Ground clearance is made as low as possible which do not cause any ruckus during travel. This E-Vehicle has more turning radius which avoids the uncomfortness during travel. This E-Vehicle helps the special people to have a safe and comfort travel from one place to another. The advantages of this E-Vehicle are, low maintenance, cost affordable, safety and comfort travel.

Revised Manuscript Received on July 10,2019.

B. Balaji, Asst. Professor/ EEE, IFET College of Engineering, Villupuram, TN, India. (balaji.bc91@gmail.com)

R. Suganya, Asst. Professor / EEE, IFET College of Engineering, Villupuram, TN, India. (suganjothi@gmail.com)

\section{EXPERIMENTAL SETUP}

The work is initiated with detailed drawing and completed with the E-Vehicle. This vehicle is the three wheeler. One wheel at front and two wheels at rear. The front wheel is connected with the steering and the rear wheel has the motor in it (i.e) Hub Motor (wheel itself has the motor). The steering consists of driving throttle, braking systems and other accessories such as horn, switches for lighting, etc., The vehicle also has comfortable seating arrangement and a cabin for placing batteries, control circuitry, etc.,

The Block diagram of the E-Vehicle is shown in fig. 2.1. which consists of various blocks in it which are explained below in detailed manner.

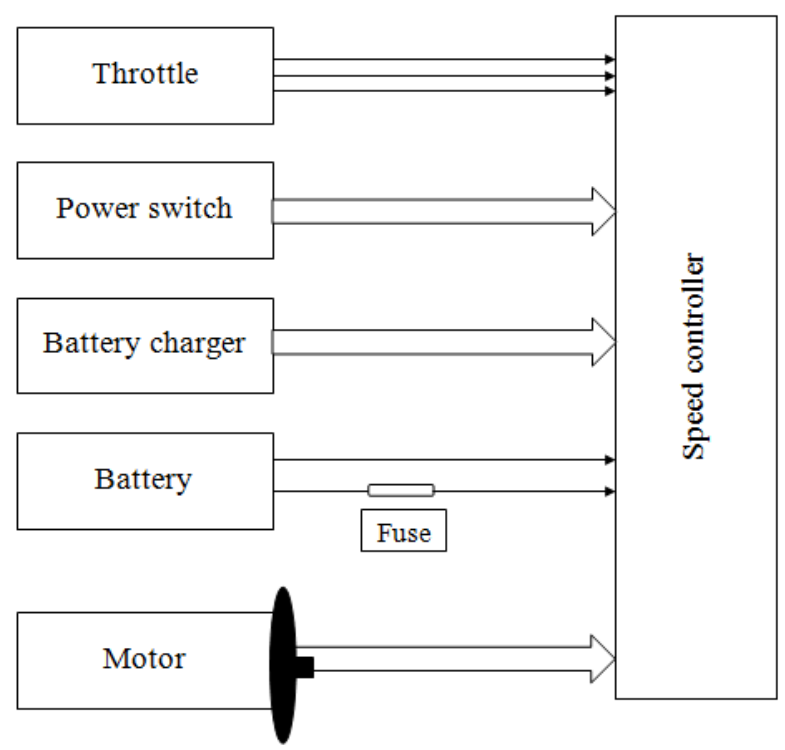

Fig.1. Block Diagram of E-Vehicle

The Various parts in the Proposed E-Vehicle are,

\section{A. Chassis - Initial Approach}

The making of this E-Vehicle initially consists of chassis making and it is developed by bending channels, boxing, welding, etc., the hindmost axle, wheels, bearing are selected according to plan procedure. Front fork is fixed and after that perforated sheet is used to cover certain area in the vehicle. The box cabin is made to withhold the batteries, control circuits, etc., and it is fixed under the seat.

Published By:

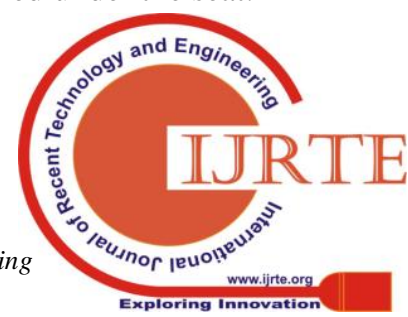


Finally the front wheel is mounted with the steering set up and the wheels which has motor (hub motor) in it is also mounted at the rear part of the vehicle. The hub motor is connected with the battery. The chassis is fixed with front and rear lights, speedometer, indicating lights, horn, etc.,

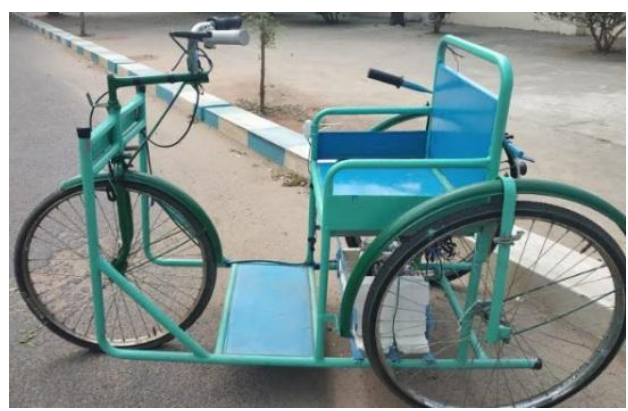

Fig.2. Chassis of the E-Vehicle

\section{B. Power Supply Element}

Power Supply Element is the key and vital element in this Vehicle. This Power Supply Element consists of battery, Plug in and Plug out cables, etc., The battery is important part in the Power Supply System and it should ensure that battery storage capacity is double the power that required in day time. Here the battery supplies voltage of about $48 \mathrm{~V}$. The battery used is lithium ion battery and each cell is of $12 \mathrm{~V}$ capacity.

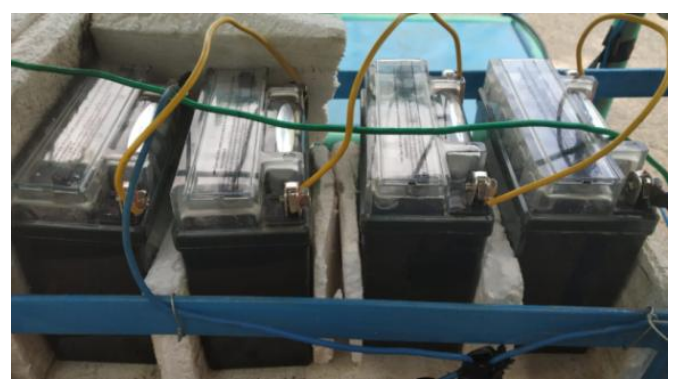

Fig.3. Li-ion Batteries in E-Vehicle

\section{Wheels}

E-Vehicle consists of three wheels, one wheel at front and IV. two wheels at rear. The rear wheel is hub motor. This hub motor is connected to the battery by means of throttle and the controller. Throttle is used to adjust the speed of the hub motor. Supporting wheels can fixed which provides furthermore mechanical strength of the E-Vehicle.

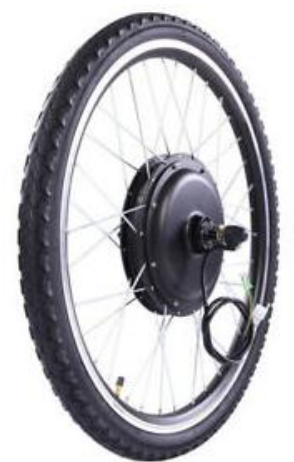

Fig.4. Hub Motor

\section{Controller}

The operation of E-Vehicle is controlled by the controller. The Vehicle control is done by electrical units. The control functions includes throttle control, braking, lighting, etc.,

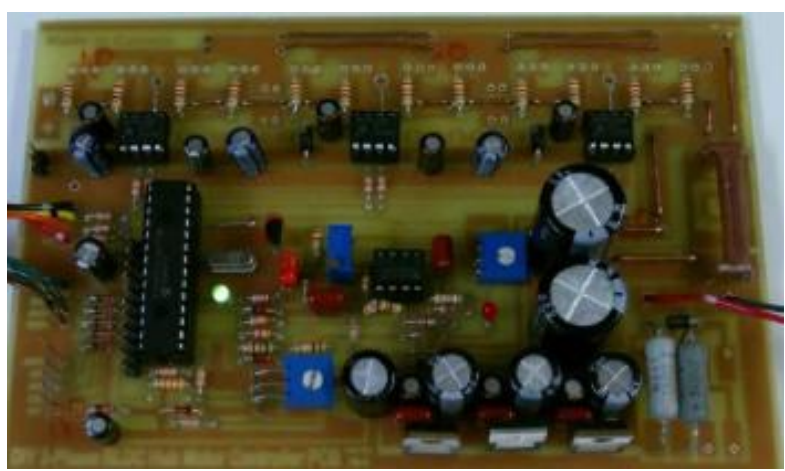

Fig.5. Control Circuit

\section{SPECIFICATION OF THE E-VEHICLE}

The Specification of the E-Vehicle is given in the below Table-1

\begin{tabular}{|c|l|l|}
\hline 1. & Motor & $\begin{array}{l}\text { Brushless DC Motor (Hub } \\
\text { Motor) }\end{array}$ \\
\hline 2. & Battery Capacity & $48 \mathrm{~V}$ \\
\hline 3. & Power Rating & $250 \mathrm{~W}$ \\
\hline 4. & Charging Time & $50 \mathrm{Mins}$ \\
\hline 5. & Maximum Speed & $30 \mathrm{Kms}$ \\
\hline 6. & Chassis & Mild Steel round rod \\
\hline 7. & Wheels & $3-1$ (front) \& 2 (rear) \\
\hline 8. & Weight & $32 \mathrm{Kg}$ \\
\hline 9. & Load Capacity & $150 \mathrm{Kg}$ \\
\hline
\end{tabular}

Table - 1; Specification of E-Vehicle

\section{BUDGET ESTIMATION OF THE E-VEHICLE \& ANALYTICAL RESULTS}

The Specification of the E-Vehicle is given in the below Table-2

\begin{tabular}{|c|l|c|}
\hline S. No & \multicolumn{1}{|c|}{ Components } & Budget (Rs./-) \\
\hline 1. & $\begin{array}{l}\text { Wheel with brushless DC } \\
\text { motor (Hub Motor) }\end{array}$ & $12,000 /-$ \\
\hline 2. & Controller Unit & $6,000 /-$ \\
\hline 3. & Lithium Ion Battery (48V) & $6,000 /-$ \\
\hline 4. & Chassis of Vehicle & $7,000 /-$ \\
\hline 5. & Other Accessories & $2,500 /-$ \\
\hline \multicolumn{2}{|c|}{ Total } & $33,500 /-$ \\
\hline
\end{tabular}

Table - 2; Budget of E-Vehicle

The below fig is the photograph of the proposed Cost Effective E-Vehicle for Physically Challenged and Aged People.

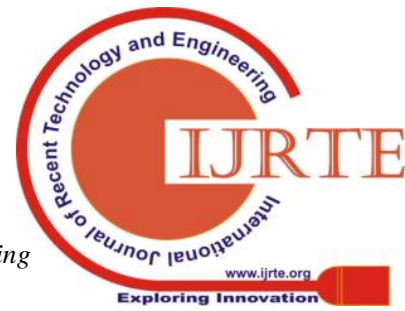




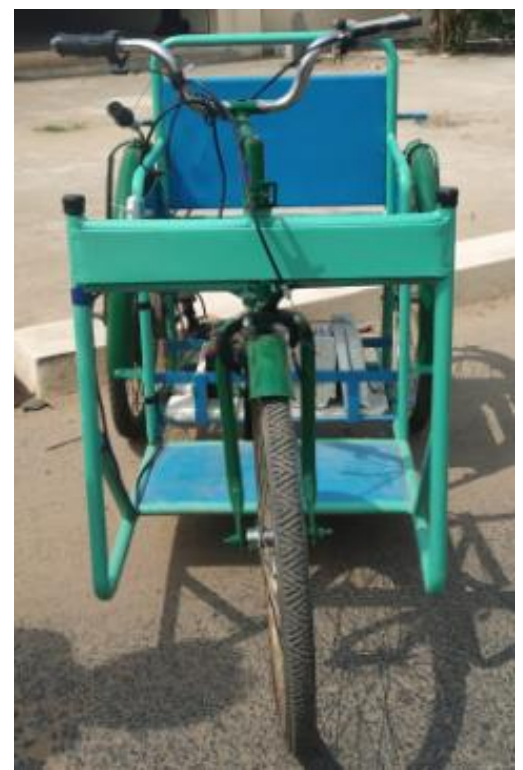

Fig.6. Proposed E-Vehicle

\section{CONCLUSION}

The work aims is to design and in making an E-Vehicle of extremely compact size to travel in indoor and outdoor areas like bus stops, bus stands, hotels, working places, etc., The E-Vehicle is made of light weight to have high range and efficiency, acceptable ground clearance between the vehicle and the road. The platform is also made on the E-Vehicle, so that the physically challenged people can survive comfortably on it. The prototype is made and it is tested manually on the road. This E-Vehicle is mainly done for financially middle class peoples, who cannot purchase other type of Electric Vehicles which are all very expensive in their view.

\section{REFERENCES}

1. Sheu, Kuen-Bao a n dHsu, Tsung-Hwa, Design and Implementation of a Novel Hybrid Electric Motorcycle Transmission, Applied Energy, Vol.83,Issue9 pp954974,Sep2006.

2. Tatyaso A. Garande, Prof. P.D. Sonawan, Prof.Dr.S.T.Chavan, Prof.G.S.Barpande, Review of Motorized Tricycle for the Disabled Person, International Journal of Science and Research, (IJSR) 201333.

3. Tong,Chia-hang and J wo,Wu-Shun,An Assist Mode Hybrid Electric Motorcycle, of Power Sources, Vol.174,Issue t,pp6168,2007.

4. Arpit Mehra, Arindam Ghosal, A-3 Wheels Electric Car for Physically Disabled people, International Journal for Innovative Research in Science \& Technology April 2012.

5. Behzad, Asaei and Mahdi, habibidoost, Design, Simulation and Prototype Production of a through the road Parallel Hybrid Electric Motorcycle, Energy Conversion and Management, Vol.71, pp12-20, July2013.

6. Chang, Shyue-Bin; Chen, Pang-Chia; Chuang, Hung-Shiang; and Hsiao, Chihching, Velocity Control with Disturbance server for Pedal-Assisted Electric Bikes, Vehicle System Dynamics, Vol.50, issue 11, pp631-51, November 2012.

7. Gupta P., Sharma S. ,S. Gupta,A. Choudhaey, K. Barman, D. Barua, A. Das, R. Gogoi, Development of an Efficient Hybrid Tricycle, All India Manufacturing Technology, Design and Research Conference, December 12th-14th, 2014.

8. Hsu,Yuan-Yong and Lu,Shao-Yuan, Design and Implementation of a Hybrid Electric motorcycle Management
System, Applied Energy, Vol.87, Issue11, pp.3546-51, November 2013.

9. Leitman, Set $\mathrm{h}$ and Brant, Bob, Built Your Own Electric Vehicle, Mc GrawHill, New York 2009, Vol. 32, pp321-26.

Fig. 3. Power Exchanging Wheel

D. Controller

The vehicle control is handled by electrical units. It includes basically pedal assist and cruise modes, hall timing, voltage cutoffs, interlock swiches etc.

III. CONCLUSION

The objective of this study was to design and develop a vehicle of highly compact to enter the building and structures like industries, Hospitals, indoor and outdoor place. The vehicle was made with light weight in order to increase its range and also to carry a better weight. The vehicle was built with a height as low as possible but the other factor, ground clearance is also considered for the suitability of Indian roads. A plat form was made in the vehicle so as the disabled persons survive with wheelchairs can also keep their wheelchairs comfortably. By wheel up or down they can accommodate in the vehicle easily without without dismount them. A prototype of this vehicle was designed fabricated and tested manually on the road.

\section{REFERENCES}

[1] Sheu, Kuen-Bao a n dHsu, Tsung-Hwa, Design and Implementation of a Novel Hybrid Electric Motorcycle Transmission, Applied Energy, Vol.83, Issue9 pp954974,Sep2006. 